\title{
La crisis ambiental en el laberinto de la sustentabilidad
}

\section{Environmental crisis in the sustainability labyrinth}

\author{
ENRIQUE LEFF (2004), RACIONALIDAD AMBIENTAL. LA REAPROPIACIÓN \\ SOCIAL DE LA NATURALEZA, SigLO XXI, MÉXICO, 509 PP., \\ ISBN: 968-23-2560-9
}

La publicación de este libro de Enrique Leff representa un suceso editorial muy importante por las escasas publicaciones que abordan aspectos epistemológicos acerca de la problemática ambiental; además de que aporta diversos análisis de interesantes experiencias alrededor de la sustentabilidad en América Latina y México; y aun cuando el libro fue publicado a fines de 2004, desde entonces ha tenido influencia en diversos círculos académicos e institucionales, por lo que resulta conveniente y pertinente discutir su estructura, los principales postulados plasmados en él y sus implicaciones sociopolíticas.

Los buenos frutos alcanzados, que son indudablemente resultado de un gran esfuerzo intelectual, son evidentes, lo cual se deriva de sus distintas lecturas; son también producto del empleo de un enfoque interdisciplinario pocas veces visto en nuestros países. Y ni qué decir que, por supuesto, el autor se enfrenta a un enorme reto que se le presenta a la sociedad contemporánea, como es el de construir una nueva racionalidad, una racionalidad ambiental, ya que, según se afirma en la contraportada del libro, y desde la ecología política:

La crisis ambiental es la crisis de nuestro tiempo. Es la crisis de la razón de la modernidad reflejada en la naturaleza. Es la crisis del pensamiento y de las formas de conocimiento con las que hemos construido y destruido el mundo y nuestros mundos de vida. El dislocamiento de la racionalidad económica devasta la naturaleza, invade la vida, rompe los ciclos económicos y degrada el ambiente. Y como dice el autor en la contraportada de este libro: "[...] La racionalidad ambiental reinventa identidades e impulsa la emergencia de nuevos actores sociales en el campo de la ecología política, que confrontan las políticas de capitalización de la naturaleza y construyen nuevas estrategias para la reapropiación social de la naturaleza”. 
Entre los propósitos de esta obra destaca la pretensión (aunque poco lograda, a mi parecer) de mirar el mundo a la luz de la crisis de civilización (que provoca el cada vez mayor desorden ambiental), y desde el Sur.

El autor se afana en encontrar la solución a la problemática discutida desde la perspectiva de las mayorías y es allí donde se encuentran en el libro los más significativos aportes, lo que le permite avanzar en el camino de la deconstrucción de la racionalidad (económica) dominante, basada en la óptica de la economía capitalista, y ayuda así a la construcción de otra racionalidad: "La racionalidad ambiental se va constituyendo al contrastarse con las teorías, el pensamiento y la racionalidad de la modernidad. Su concepto se fue gestando en la matriz discursiva del ambientalismo naciente, para ir creando su propio universo de sentidos" (p. xv).

\section{Sustentabilidad y racionalidad ambiental}

El libro (con nueve capítulos) va tejiendo conceptualmente la racionalidad ambiental a partir de una revisión crítica del pensamiento de la modernidad y la posmodernidad, en donde rechaza y toma simultáneamente de diversos autores, la materia prima con la cual va elaborando de manera gradual el concepto y, a partir de éste, se pretende iluminar al lector con los temas más acuciantes del crítico problema referido que se vive en el ámbito global (acicateado por el cambio climático, tema ausente).

En esa forma participa de una diversidad de debates que incluyen, en principio: a Marx y su teoría del valor-trabajo; una exposición de los aciertos y desaciertos de Murray Bookchin y el naturalismo dialéctico; la hiperrealidad de Jean Baudrillard; el debate sobre la economía ecológica a partir de Georgescu-Roegen; se reposiciona a Weber, y se nutre de Foucault, Habermas, Levinas, Derrida, George Bataille...

La obra se inscribe en la crítica del discurso institucional de la sostenibilidad, ofreciendo la propuesta de una reapropiación social de la naturaleza, como se manifiesta en el subtítulo del mismo y utilizando un enfoque que abraza la idea de una sustentabilidad, no instrumental sino sustantiva, podemos decir.

En este punto, y de entrada, se manifiesta una primera contradicción, pues los términos sostenibilidad y sustentabilidad son simples traducciones equivalentes del mismo vocablo inglés que 
es sustainable; entonces, la distinción sólo tiene sentido en lengua castellana, siendo irrelevante en otros idiomas.

Sin embargo, en ese terreno es pertinente distinguir entre ambas traducciones de la misma palabra, porque, en efecto, en nuestro idioma semánticamente denotan significados distintos, como lo destacan diversos autores (Segura y Bartholomew, 1992; Del Amo y Ramos, 1996; Torres, 1999), y el mismo Leff en este texto. Así, el concepto de sostenibilidad se relaciona precisamente con una visión reduccionista de la cuestión ambiental, referida a mantener el uso (y abuso) actual (y futuro) de los recursos naturales, aunque con el propósito de aminorar sus perniciosos y devastadores efectos; mientras que el de sustentabilidad se refiere más bien a la necesidad de interiorizar el daño ecológico:

La ambivalencia del discurso del desarrollo sostenible se expresa ya en la polisemia del término sustainability, que integra dos significados: el primero, traducible como sustentabilidad, implica la incorporación de las condiciones ecológicas -renovabilidad de la naturaleza, dilución de contaminantes, dispersión de desechos- del proceso económico; y el segundo, que se traduce como sosteniblidad, implica perdurabilidad en el tiempo del proceso económico (p. 103).

En esto tiene razón el autor, quien de esa manera se separa del discurso convencional de numerosos autores de España e Hispanoamérica. Sin embargo, si la crítica es demoledora en el texto en cuanto al empleo del término sostenibilidad, resulta en cambio apologética, en relación con el de sustentabilidad, ya que si bien es un término más complejo que el anterior (porque además de sostener, significa alimentar, argumentar; es por lo tanto más rico éste que aquél), supone una pregunta obvia: ¿por qué una traducción resulta mecanicista y la otra profunda cuando provienen las dos de una distinta traducción del mismo vocablo sustainable? Y entonces: los defectos de una traducción, ¿por qué no lo son de la otra?; o bien, hay que decir que, dentro de la amplia gama de visiones sobre la sustentabilidad, la comentada sería tan sólo una de ellas, la mayoría de las cuales siguen siendo instrumentalistas y prescriptivas; y ello además de que los términos de sostenibilidad y sustentabilidad poseen la misma raíz.

Todo esto se pone de manifiesto cuando se define lo que sería el vehículo que permitiría alcanzar una racionalidad ambiental, esto es, la reapropiación social de la naturaleza, entendida como la aplicación de diversas estrategias dirigidas al desarrollo sus- 
tentable. Entonces queda claro que, para el autor, la racionalidad ambiental y el desarrollo sustentable van de la mano.

Lo anterior es el soporte epistémico del libro, y no es que le quite méritos, pero sí lo circunscribe, de manera particular, a una determinada corriente sobre la sustentabilidad. Sin embargo, era indispensable ir más allá de esta última en el texto; en cambio, se muestra sumamente complaciente con el discurso institucional que es necesario superar.

Se puede agregar que, por la magnitud de la obra, era fácil caer en algunas repeticiones como se constata mediante el empleo de los conceptos mencionados. Sin embargo, ello se puede evitar cuando se trata de que el trabajo teórico se pueda traducir en prácticas políticas y de gestión local, comunal y regional de los recursos naturales.

\section{La racionalidad ambiental y la reapropiación social de la naturaleza}

El libro (cap., “Teoría del valor y fuerzas productivas de la naturaleza") comienza enfocando sus baterías contra la ley del valor en el capitalismo (en la interpretación marxista) y el rechazo de la teoría objetiva del valor (sin cuestionar en cambio la teoría subjetiva), pero planteando el debate en otros términos (el valor cualitativo). Sin embargo, ello se abandona inmediatamente y se llega de esa manera a un análisis teórico en el que no se encuentra una estructura de lo real subyacente en el mismo; esto es, la necesidad de mostrar cómo las actividades humanas se engarzan con las de la naturaleza.

Por eso, cuando entra después a la discusión sobre la economía ecológica (cap. 4), ésta no se encuentra entrelazada con una teoría del valor en general y tampoco del valor-trabajo en particular; en consecuencia, los problemas epistemológicos quedan sueltos, alcanzando cierto nivel de coherencia sólo mediante la aplicación de varias fórmulas retóricas (aunque en el buen sentido) a lo largo del libro.

En principio, Leff considera que la influencia de la ley del valor y de la teoría aludida ya es inoperante por una causa tecnológica, por ello afirma que: "Desde el momento en que la acumulación de capital induce la producción y la aplicación tecnológica de la ciencia como un requisito para la reproducción del capital, se vuelve imposible el cálculo del valor que contiene el capital incorporado a una nueva técnica, y en consecuencia la 
cantidad de valor que transmite la mercancía que produce" (p. 27). Pero desde luego una cosa es el cálculo del valor (tarea que se caracterizó en las economías centralmente planificadas) y otra son las leyes de su funcionamiento, en tanto constituye una relación social (de producción). "Al desaparecer la ley del valor como principio cuantitativo determinante de las transformaciones sociales, las prácticas políticas dejan de ser el efecto de un mecanismo automático" (p. 34).

La negativa a aceptar la teoría del valor-trabajo, le condujo a algunas dificultades teórico-metodológicas, como la de proponer una teoría del valor cualitativo (que luego desdeña), la cual es, sin embargo, inherente al análisis de Marx, ya que la materialización del trabajo social es la sustancia del valor, y ésta corresponde al concepto de cualidad (Hegel).

La parte cuantitativa del valor está dada por su magnitud, esto es, por el trabajo socialmente necesario para la producción de un valor-mercancía; no obstante, la determinación de la magnitud del valor ha sufrido cambios de contenido y de forma con la expansión de la red de corporaciones trasnacionales que controlan mercados y territorios, y fijan precios y rentas de monopolio.

Pese a la negación del valor-trabajo (y su conversión de signo en simulacro siguiendo a Baudrillard), se plantea que la racionalidad ambiental supone una estrategia basada en "la valorización cultural económica y tecnológica de los bienes y servicios ambientales de la naturaleza" (p. 43). Lo cual provoca ruido, pues lo que falta en la explicación, es precisamente una teoría del valor en general (y dentro de ella, la relación entre una teoría objetiva y una subjetiva a partir del pluralismo metodológico). Y eliminar, sea en forma teórica o práctica la importancia del trabajo, aun a partir de las leyes de la termodinámica, resulta una tarea inútil aunque política (y económicamente) correcta, ya que necesariamente son compatibles entre sí.

En el capítulo 2 ("La complejidad ambiental y el fin del naturalismo dialéctico”), retomando la crítica a la teoría de sistemas (a la cual se había adscrito el llamado ecodesarrollo), se rechaza la idea de un naturalismo dialéctico propuesta por Murray Bookchin, a partir de un monismo cognitivo característico de su obra, en la que "La naturaleza segunda aparece así como un epifenómeno de la exclusión natural de la naturaleza” (p. 51).

Con ello afirma correctamente que "el naturalismo dialéctico como principio organizativo de la realidad y las ideas se ha desplazado hacia la teoría constructivista y hermenéutica, donde el 
concepto mismo de naturaleza aparece como una construcción social, mediada por significaciones culturales" (p. 81).

En el capítulo 3 ("El retorno del orden simbólico: la capitalización de la naturaleza y las estrategias fatales del desarrollo sostenible"), pareciera complaciente con Jean Baudrillard, de quien había destacado "el desplazamiento de la economía política del signo -fundada en un sistema de representaciones- hacia el campo de la simulación -regida por la ley del código-” (p. 39).

Así, en este capítulo afirma que "el juego de los opuestos se abre en la posmodernidad hacia un pensamiento de la diferencia, atrapado por el simulacro del orden simbólico" (p. 90); lo cual conduce a una construcción del mundo que "ha derivado en una imposibilidad de aprehender lo real, ha engendrado una hiperrealidad que está fuera de toda ontología y de toda epistemología [...] en la era del código el conocimiento se aparta cada vez más de su referente fáctico, para construir realidades virtuales y mundos de vida flotantes" (p. 89).

Y ello, ¿qué tiene que ver con la crisis ambiental? Lo tiene por el hecho de que "los procesos ecológicos y simbólicos son reconvertidos en capital, natural humano y cultural” (p. 105).

Por tanto:

el discurso de la globalización aparece así como una mirada glotona más que con una visión holística; en lugar de aglutinar y dar integridad a la naturaleza y la cultura, las fragmenta como partes constitutivas del desarrollo sostenible. [...] Esta operación simbólica somete a todos los órdenes del ser los dictados de una razón global y universal [...] Las estrategias fatales del discurso del "desarrollo sostenible", resultan de su pecado capital: su gula infinita e insaciable (p. 109).

Nuestro autor también considera que es en el terreno de la ecología política, en la que los antagonismos de las luchas sociales se definen en términos de identidad, territorialidad y sustentabilidad (p. 115) donde plantea, sobre la base del principio de productividad neguentrópica, construir una racionalidad ambiental y deconstruir la racionalidad económica (pero aun la misma racionalidad ambiental de Leff implicaría también otra racionalidad económica). Y además hay que preguntarse si, en esa racionalidad ambiental, desaparecería la racionalidad capitalista o bien se trataría efectivamente de otra, ¿no se entra aquí en el terreno de la economía ecológica crítica?, y también: ¿qué pasa cuando la economía se queda, según esto, sin ley del valor? (p. 134). 
Lo anterior se revisa en el capítulo cuarto ("La ley límite de la naturaleza: entropía, productividad neguentrópica y desarrollo sustentable"), en el que considera la entropía como una ley limite, que es la más económica de todas las leyes naturales, y que "es la base de la economía de la vida en todos los niveles", siguiendo a Georgescu-Roegen (1975: 137).

Se agrega que la entropía es un factor adicional que cuestiona la validez de la teoría del valor fundada en el trabajo y el cambio tecnológico. Aunque la entropía se expresa básicamente en la economía mediante el proceso de desvaloración (destrucción del valor).

Además, se insiste mucho en la importancia de la productividad de la naturaleza (p. 148). Pero la que ha faltado, más bien, es la productividad natural del trabajo (por ejemplo, los trabajos de conservación ecológica).

Se puede señalar que en la convergencia de órdenes ontológicos diversos (como se reconoce en el texto), la relación entre natura y técnica está mediada precisamente por el trabajo.

También hay que reconocer que se hace una propuesta acertada en el sentido de llegar a una economía que esté basada "entre el balance de la productividad neguentrópica de biomasa y la producción entrópica de los procesos de transformación tecnológica y al metabolismo de los seres vivos" (p. 155).

Y ello es lo opuesto a la economía actual en la que se transforman recursos de baja entropía, en desechos de alta entropía y, en consecuencia, "la crisis ambiental ha sido el gran aguafiestas en la celebración del triunfo del desarrollismo, expresando una de las fallas más profundas del modelo civilizatorio de la modernidad. La economía, la ciencia de la producción y la distribución, mostró su rostro oculto en el disfraz de su racionalidad contranatura" (p. 181).

El capítulo quinto ("La construcción de la racionalidad ambiental") es central porque se trata del eje conceptual del libro, incluyendo en dicha racionalidad los siguientes factores:

La construcción de un nuevo paradigma productivo fundado en principios y bases de racionalidad ambiental, implica una estrategia de deconstrucción de la racionalidad económica a través de actores sociales capaces de movilizar procesos políticos que conduzcan hacia las transformaciones productivas y del saber para alcanzar los propósitos de la sustentabilidad, más que a través de normas que puedan imponerse al capital y los consumidores para reformar la economía” (p. 191). 
Aunque ello es insuficiente sin modificación en el comportamiento de la economía real.

Luego se afirma que la racionalidad ambiental no es la expresión de una lógica o de unas leyes resultado de un conjunto de normas, significaciones, intereses, valores y acciones que no se dan fuera de las leyes de la naturaleza, pero que la sociedad no se limita a imitar (p. 211).

Y siguiendo a Weber incluye la articulación de cuatro niveles de racionalidad (p. 215): 1) racionalidad sustantiva (establece un sistema de valores); 2) racionalidad teórica (construye su conceptos); 3) racionalidad técnica (produce vínculos funcionales y operacionales entre objetivos sociales y las bases materiales del desarrollo sustentable); y 4) racionalidad cultural (sistemas de significación).

Asimismo afirma que la racionalidad ambiental rompe con el principio de la supremacía del principio de la racionalidad instrumental, porque debiera incluir una dialéctica que no se deduce de una ontología de lo real, sino que surge de una dialógica guiada por la otredad (p. 211). El autor adopta, pues, un elemento de multirracionalidad y policentrismo, aspectos que fue necesario explorar.

Por su parte, la importancia de la racionalidad cultural queda de manifiesto cuando en el capitulo 6, sobre "La ecología política y el saber ambiental" (y en él, la discusión sobre la sociología del conocimiento), entiende a aquélla como la política de la reapropiación de la naturaleza, no sólo a partir de las luchas ocurridas por la distribución de los bienes materiales, sino sobre todo por los valores de significación” (p. 269).

Antes había afirmado que las nuevas identidades se constituyen en el campo de una política de la diferencia, además de que "la crisis ambiental es una crisis del concepto de naturaleza (como explotación y exclusión)” (p. 259).

Y lo anterior hay que entenderlo "frente a una hibridación de órdenes ontológicos considerados hasta hace poco como entidades autónomas y separadas (el orden físico, biológico, cultural, simbólico, tecnológico" (p. 272). Y además, en el plano de "la disolución del poder de una minoría privilegiada para sojuzgar a la mayoría excluida se convierte en una tarea primitiva y en donde la naturaleza y la cultura se resisten a tal sometimiento" (p. 197).

Aparece entonces un hueco ante la falta de explicación mayor sobre la reapropiación social de la naturaleza, sobre todo frente a los procesos de privatización a ultranza, porque no se estudia 
ésta como una evolución de las distintas formas de propiedad; aquí se tuvo que actualizar la idea del cambio sistémico y sus posibles orientaciones.

En el capítulo 7 ("Racionalidad ambiental, otredad y diálogo de saberes") se destacan los aportes de Habermas en relación con el tema de la racionalidad a partir de la teoría de la acción comunicativa: "Habermas deja atrás el paradigma del conocimiento de lo real fundado en lo imaginario de la representación para acercarse a un entendimiento del mundo, fundado en una racionalidad comunicativa" (p. 306).

De esa forma, el saber ambiental se define como el campo de la externalidad (el Otro) del conocimiento científico; y el diálogo de saberes como la relación de otredad que abre la historia hacia un futuro sustentable (p. 324). Y tiene toda la razón, ya que la crisis ambiental tiene en su origen una causa humana, derivada de la incomunicación humana. Así pues: "El diálogo de saberes como tensión y solidaridad entre seres culturales que dialogan desde sus diferencias no siempre integrables, ni 'traducibles', se plantea como condición de la democracia en el campo de la sustentabilidad" (336).

El capítulo 8 ("Cultura, naturaleza y sustentabilidad: pulsión al gasto y entropía social") se puede resumir diciendo que "la racionalidad de la sustentabilidad abre la posibilidad de construir un nuevo paradigma productivo, fundado en los potenciales de la naturaleza y en la recuperación y el enriquecimiento del conocimiento que a lo largo de la historia han desarrollado diferentes culturas sobre el uso sustentable de los recursos naturales" (p. 355).

Pero se equivoca cuando señala que "los principios de la racionalidad ambiental definen así un concepto de productividad sustentable que trasciende la oposición entre conservación y crecimiento" (p. 377). Se equivoca porque la sustentabilidad puede absorber las condiciones ecológicas, pero aun así seguirá estando presente esta contraposición porque el crecimiento y conservación pueden ser compatibles o bien incompatibles; son dos situaciones diferentes.

En cuanto a la reapropiación de la naturaleza, ésta se define como "una resignificación de la naturaleza en los senderos de la vida que abre la existencia” (p. 394), lo que resulta muy vago.

Luego caracteriza los movimientos ambientalistas por los siguientes objetivos (pp. 400-401): 
1) Una mayor participación en los asuntos políticos y económicos y en la gestión de los recursos naturales.

2) Su inserción en los procesos de democratización del poder político y la descentralización económica.

3) La defensa de sus territorios, sus recursos y su ambiente, más allá de las formas tradicionales de lucha por la tierra, el empleo y del salario.

4) La construcción de nuevos modos de producción, estilos de vida y patrones de consumo apartados de los modelos capitalistas y urbanos globales, transnacionales y extranjeros.

5) La búsqueda de nuevas formas de organización política, diferentes de los sistemas corporativos e institucionales de poder.

6) La organización en torno a valores cualitativos (calidad de vida), más allá de los beneficios derivados de la oferta del mercado y del Estado benefactor.

7) La crítica de la racionalidad económica fundada en la lógica del mercado, la maximización de la ganancia y la eficiencia tecnológica, y a los aparatos de control económico y coerción política e ideológica del Estado.

En el capítulo 9 ("El movimiento ambiental por la reapropiación social de la naturaleza") ante todo refleja la pluralidad: "A diferencia de la apropiación de los medios de producción, guiada por las fuerzas naturales desencadenadas y constreñidas por la tecnología, las acciones sociales orientadas por la racionalidad ambiental plantean la apropiación de la naturaleza dentro de una diversidad de estilos de desarrollo sustentable" (p. 433).

Y luego se deslinda de la revolución:

Si en algo se distingue el ambientalismo [¿̇a cuáles se refiere?, GTC] del marxismo ortodoxo es que no busca tan sólo un cambio [¿̇y en qué dirección?, GTC] en las formas de propiedad de los medios de producción [...] se trata de una lucha por la reconstrucción del proceso productivo, en la cual se mezclan la lucha por el territorio, por las tradiciones e identidades culturales, por los saberes productivos y con los principios de nuevas ciencias y tecnologías (agroecología, economía ecológica, biotecnología) para construir un nuevo paradigma de productividad que articula los procesos ecológicos, tecnológicos y culturales internalizando sus saberes en las prácticas productivas de las comunidades" (p. 439).

Aunque aquí Leff parece no abandonar la racionalidad económica que tanto cuestiona, insistiendo en que la centralidad de la racionalidad ambiental es el paradigma de la productividad; 
pero además, hay que considerar a la sociedad como un todo y no sólo a las comunidades rurales: "De allí que el concepto de desarrollo sustentable cobre su sentido más amplio en los procesos de producción rural" (p. 421); pero entonces el desarrollo sustentable tendría, en efecto, un alcance muy limitado.

Y finaliza:

Las identidades del seringueriro, del afrocolombiano, o del indígena zapatista desconstruyen los soportes teóricos, jurídicos, económicos y políticos que sostienen la territorialidad con la que se debaten y confrontan los hombres y mujeres para construir su singular forma de ser: su autonomía. La ecología política de esos movimientos está fertilizando territorios donde se plantan las identidades [...] de todas las etnias de este continente y del mundo entero que hoy en día despliegan sus luchas por la reapropiación de la naturaleza y la reexistencia de su cultura (p. 456).

\section{Aspectos críticos}

En realidad, las principales aportaciones de esta investigación teórica (menos práctica) se centran alrededor de la categoría que le da título a la obra, la cual pretende rescatar el concepto de racionalidad sustantiva weberiana asociándola ahora a su propuesta de una racionalidad ambiental. Y no obstante que en la complejidad que implica la dimensión ambiental, no todo es racional (aunque el texto de marras trata de subsumir otras dimensiones bajo este concepto), no obstante se continúa con el pensamiento racionalista del Norte, y poco está presente la mentalidad y desarrollo teórico del Sur (aunque desde luego Enrique Leff es un destacado representante del Sur; de un ambientalismo basado en las autonomías, y éstas incluyen el pensamiento local).

Mientras que la principal debilidad del texto radica en una suerte de monotonía alrededor de la categoría central que aparece así como una caja de Pandora, de la cual Leff, como un moderno alquimista, extrae (y seduce con) múltiples teorías a discutir en torno a la crisis ambiental, que van brotando alrededor de la centralidad del concepto de racionalidad ambiental, plasmando una estructura argumental que representa un auténtico laberinto, ya que impide apartarse del único camino que ofrece esta denominada nueva racionalidad.

El método empleado no parece del todo convincente, ya que se sigue un orden de exposición cuyos temas son variados y sólo se entrelazan mediante la reiteración del postulado principal señalado. Tal circunstancia lo aleja de la dialéctica de lo concreto; esto 
es, porque en la construcción de su objeto de investigación, mediante la confrontación (o mejor dicho, conversación) con diversos autores, no resulta adecuado el hilo conductor subyacente, ya que se comienza con una crítica de la teoría del valor-trabajo, pero después el referente es la hermenéutica, o la crítica a la economía ecológica (en algunas variantes), y luego se van repasando una diversidad de temas, aunque ciertamente todos vinculados con la problemática ambiental, directa o indirectamente.

El ensamblaje de textos, por lo demás muy bien escritos, es valioso de por sí, y en efecto le quita cierto mérito a esta gran aventura intelectual, pues es como si fuese una moderna Odisea, aunque sin retorno a casa. Quizás ese hueco lo puedan llenar obras posteriores.

Se hace gala de erudición y alta cultura pero, en términos epistémicos y metodológicos, el discurso gira alrededor del concepto central, lo que impidió exponer con más claridad las principales conexiones entre todos los temas tratados.

Sin duda bordar sobre el mismo concepto (la racionalidad ambiental) enriquece el debate, dada la intención de construir y definir la complejidad ambiental, el ambiente mismo, como un proceso continuo y abarcador; tarea realizada parcialmente en otros textos ${ }^{1}$ de manera certera, pues en ellos se ha alertado sobre las definiciones mecanicistas, sin ignorar los diálogos entre las esferas particulares del conocimiento y de la realidad social

Por otro lado, ante la abrumadora cantidad de citas y referencias bibliográficas (que pueden disfrutarse aparte), el autor se desvía un tanto del orden lógico y metodológico del texto (así como histórico), lo que no permite entender adecuadamente las propuestas intelectuales sobre la dimensión de la racionalidad ambiental, a la cual se le asignan las siguientes características:

Es una teoría que orienta una praxis a partir de los principios que han ordenado y legitimado la racionalidad técnica e instrumental de la modernidad. Es una racionalidad -en sentido weberiano- que articula una racionalidad técnica e instrumental con una racionalidad sustantiva; es una racionalidad que integra el pensamiento, los valores, la acción abiertas a la diferencia, la diversidad y pluralidad de racionalidades es una razón deconstructora de la racionalidad de la modernidad (p. 339).

${ }^{1}$ Ver de Enrique Leff (coord.), La complejidad ambiental”, Siglo xxi, México, 2000. 
Y lo anterior tiene un enorme poder de seducción en torno a la reflexión sobre la trascendencia del ambiente en la vida de la sociedad y sus integrantes y el territorio en que interactúan.

Sin embargo, el autor no se percata de que, en el fondo, no hay una sola racionalidad ambiental, sino al menos dos, que son: la depredadora y la alterna. En el texto ambas se cruzan de forma continua, pero sólo se nombra la racionalidad ambiental en genérico, lo que limita enormemente el análisis, pues era necesario saber cuáles son los componentes (la diferencia específica) que oponen una racionalidad alterna a la racionalidad capitalista; siendo ambas, finalmente, racionalidades ambientales (en una, el ambiente aparece como atributo del capital; y en la otra, a la inversa), porque si bien las dos dan cuenta del ambiente, lo hacen de manera diferente: en tanto una relación en la que el ser humano se sirve de la naturaleza; o bien como en la que el ser humano también sirve a los ecosistemas. De esa forma, el ambiente es un resultado de estas dos fuerzas (humano-naturales) que fluyen en sentidos opuestos pero incorporando diferentes niveles de entrecruzamiento y de equilibrio, de homeostasis ecosocial. Además de que la racionalidad capitalista es tanto instrumental como sustantiva, teórica, etcétera.

La necesidad de producir sus propios conceptos, en ocasiones también llevó al autor a ensimismarse en ello, no ofreciendo la otra crítica, la que también era necesaria para emprender la deconstrucción de la propia racionalidad ambiental, y el discurso de la sustentabilidad (que son los ejes de la obra), dándoles vuelta y sin aterrizar en conceptos más operativos, más prácticos, y a la vez con una mayor profundidad y organicidad cognitiva y analítica, así como de alcance en el logro de la movilización ciudadana.

Pero, por otro lado, la continua indagación alrededor del discurso de la reapropiación social de la naturaleza en ocasiones lo conduce a mantenerse en el esquema del dominio humano de esta última. En consecuencia, se afirma la negación de la naturaleza (en ésta y obras anteriores ${ }^{2}$ ) por el capital, lo que no es exacto pues se trata más bien de un sometimiento (lo que implica una afirmación de la naturaleza en tanto constituye una fuerza productiva del capital).

Y es que, en realidad, resulta más correcto hablar de la reapropiación social de la vida (y no sólo de la naturaleza), puesto

${ }^{2}$ Por ejemplo, Ecología y capital. Racionalidad ambiental, democracia participativa y desarrollo Sustentable, Siglo xxI, México. 
que sin la reapropiación social en los ámbitos económico y cultural, no será posible la reapropiación social de la naturaleza. Y si bien ésta es una condición de aquélla y actúan de manera conjunta, el autor plantea (p. 439) la necesidad de nuevos modos de producción (pero sin hablar de detener el modo depredador) para alcanzar la racionalidad ambiental; sin embargo, casi siempre se sugiere que no es indispensable, aunque sí posible, dicho cambio sistémico. Por ello, en vez de la reapropiación social de la economía y la sociedad, los cambios proclamados en el texto se limitan más bien a cambios en la relación con la naturaleza (y en la práctica el territorio).

Se puede afirmar que no se logró rebasar el discurso convencional de la sustentabilidad y del ambiente; se cae así en la trampa de una sustentabilidad en cierta medida apolítica.

Pero como todo encanto, éste deriva en desencanto. Así, brillantes exposiciones donde se critican o apologizan ciertos aspectos fundamentales para la interpretación de la complejidad ambiental, son tan interesantes que pueden leerse por separado; sin embargo, también se pueden mencionar algunos equívocos y ausencias.

Así, sobrevalora sus propuestas y no deja espacio para la autocrítica. Y es que la sustentabilidad es un discurso que, al no romper con las incompatibilidades en las que está inserto, él mismo se vuelve incompatible con la necesidad de construir un mundo alterno, o, como lo entiende Leff, en la ruta de la construcción de una racionalidad ambiental. Asimismo, queda encajonado en el paradigma de la posmodernidad, aunque era mejor ubicarse al amparo de una sociedad alterna.

Frente a la edificación de una racionalidad ambiental, se presentan numerosos obstáculos tanto teóricos como prácticos. Entre los segundos se puede señalar el tratar de confrontar la orientación ideológica de las propuestas alternativas con los principios de la sustentabilidad, lo cual resultó satisfactorio; en cambio, respecto a los primeros, el abordar el nuevo paradigma desde la racionalidad tuvo sus ventajas, que han sido un tema discutido, pero también insuficiencias.

Entonces, aunque la principal dificultad consistió en encerrar la propuesta alterna alrededor de la racionalidad, se hace a un lado otros aspectos que son de enorme trascendencia y que conforman la inteligencia humano-social, exagerando así sobre la importancia de la categoría de racionalidad (que se fundamenta en Weber) y de la racionalidad misma. 
Pese a todo lo dicho, el aporte principal del libro de marras se encuentra en el terreno de la economía, la sociedad y el territorio cuando el autor plantea el principio de producción neguentrópica caracterizado como un balance entre la energía y la materia disipada, y la generación de biomasa (p. 155), lo que supone aspectos de índole económica, social y territorial.

Se confrontó la racionalidad instrumental y sustantiva, entre otras, pero se dejó de lado la discusión más allá de la racionalización, independientemente de sus manifestaciones. Por ejemplo, no obstante que se destaca la trascendencia de la racionalidad comunicativa de Habermas, hay que reconocer que se trata de una veta que simplemente se anuncia, mas no se explora suficientemente.

\section{Conclusión}

La propuesta de la racionalidad ambiental (y de la reapropiación social de la naturaleza) es amplia -y en ocasiones ambigua-, y pese a que las limitaciones alrededor de ella pueden pasar a un segundo plano, de todas maneras queda en el aire la duda de saber si el autor se vuelve o no portavoz del discurso institucional de la sustentabilidad, con sus virtudes y fracasos. Y derivado de la anterior, podemos preguntarnos también si la racionalidad ambiental es por naturaleza anticapitalista, o ipuede en cambio envolver (y revolver) los principios civilizatorios de esta sociedad?; y si ello se debe a que precisamente no cuestiona las creencias que tiene la sociedad moderna sobre la sustentabilidad.

La dificultad de construir una racionalidad ambiental que supere el economismo y el ecologismo, pero sin cambiar el modo de producción, representa un sueño imposible, aunque el enorme esfuerzo por construir una racionalidad de la sustentabilidad dio buenos resultados. Sin embargo, las críticas al desarrollo sustentable están ausentes, pero sin la deconstrucción del discurso de la sustentabilidad (que tiene un fundamento economicista en las dos variantes ya analizadas) realmente no se puede realizar el objetivo principal, que es la reapropiación social de la naturaleza (o como se destaca en esta nota crítica, la reapropiación social -e individual- de la vida).

De por sí, la construcción de una racionalidad ambiental es una tarea (colectiva) gigantesca. De esta forma, el libro se puede considerar un importante avance en la lucha por revertir la crisis ambiental y sus secuelas (apoyado en la arquitectura semiótica 
(y hermenéutica) desplegada a lo largo de sus capítulos), que junto con otros esfuerzos, coadyuvará sin duda a darle un carácter vital a lucha por la transformación de la crisis ambiental en el sentido que sugiere la racionalidad ambiental. Para alcanzar ésta, no obstante, no fue suficiente el enfoque empleado en el libro reseñado, por lo cual es necesario dar los pasos indispensables para conjuntar esfuerzos en dirección a un mayor avance de la teoría socioambiental crítica y de esa manera contribuir a detener la depredación planetaria.

Se puede hacer una última pregunta: ¿y el desencanto de la posmodernidad? Ello nos lleva a pensar lo no pensado en el marco de una sociedad alterna y frente a la insuficiencia de los procesos de racionalización; de la racionalidad en cuanto tal. Así, es necesario incluir, en la perspectiva de la transición ambiental, otros aspectos como la sentimentalidad, las inteligencias moral, espiritual y sociocomunitaria, y que no pueden todos reducirse a la racionalidad (aun la sustantiva), tanto económica, ni como ahora se propone, ambiental.

De todas formas, el libro es sumamente útil para un lector interesado en repensar la crisis ambiental global, y así poder entender mejor tanto las condiciones como las posibilidades para la reconstrucción de la relación entre la sociedad y el ambiente.

\section{Bibliografía}

Del Amo, Silvia y José María Ramos (1996), Desarrollo sostenible, Pronatura, México.

Georgescu-Roegen, Nicholas (1975), "Energía y mitos económicos”, El Trimestre Económico, 168, Fondo de Cultura Económica, México, pp. 779-860.

Segura, Olman y Joy Bartholomew (1992), Desarrollo sostenible y políticas económicas en América Latina, DEI, San José.

Torres-Carral, Guillermo (1999), Sustentabilidad y compatibili$d a d, \mathrm{UACH}$, México.

Recibida: 16 de agosto de 2008. Aceptada: 16 de febrero de 2009. 
Guillermo Torres-CARRAL Universidad Autónoma Chapingo Correo-e: gatocarr@hotmail.com

Guillermo Torres Carral. Es doctor en ciencias agrícolas por la Universidad Agrícola de Varsovia, Polonia (1987). Hizo la maestría en economía agrícola y política agraria en la misma universidad (1984). Asimismo, es egresado de la Facultad de Economía de la UNAM (1977). Se desempeña como profesor-investigador de tiempo completo en el Departamento de Sociología Rural de la Universidad Autónoma Chapingo (en los programas educativos del doctorado en ciencias agrarias, de la maestría y en la licenciatura en sociología rural, y del doctorado en educación agrícola superior). Desde 1992 pertenece al Sistema Nacional de Investigadores (SNI). Sus líneas de investigación son: economía ecológica, alternativas del minifundio mexicano, nueva ruralidad y desarrollo sustentable en México. Entre sus publicaciones se encuentran los siguientes libros: Introducción a la economía politica ecológica, Plaza y Valdés-UACH, México (2001); Civilización, ruralidad y ambiente, Plaza y Valdés-UACH, México (2003); en coautoría, Agricultura ecológica y reconstrucción social, $\mathrm{UACH}$, México (2004); Poscivilización: guerra y ruralidad, Plaza y Valdés-UACH, México (2006); El desarrollo sustentable en México, Plaza y Valdés-UACH, México (2009). Y los siguientes artículos: "El campo mexicano: los caminos del desarrollo rural sustentable”, Revista Agro Nuevo, año 2, 15, SRA, México, pp. 139-171 (2006); "El pago de los servicios ambientales y las comunidades indígenas", RA XIMHAI, año 2, 1, México, pp. 187-208 (2006); "La Ley de Desarrollo Rural Sustentable y el campo mexicano”, $R e$ vista de Geografía Agrícola, 40, UACH, México, pp. 55-72 (2008). 